\title{
de Lucas, Javier. Decir No. El imperativo de la desobediencia. Tirant lo Blanch Valencia, 2020.
}

\author{
María José Añón Roig \\ Institut de Drets Humans \\ Universitat de València
}

Fecha de recepción 10/04/2019 I De publicación: 15/06/2020

Se ha señalado el año 2013 como el momento en que se incorporó a las universidades norteamericanas una generación de estudiantes marcada por un agudo sentimiento de seguridad y fuertes exigencias de protección. Estudiantes, como los que también pueden encontrase en Europa, poco dispuestos a cuestionar su propia forma de pensar (aceptabilidad de la censura, prohibición del debate y justificación de un punitivismo extremo) y prontos a evitar la confrontación argumentativa y racional sustituyéndola por formas puramente emocionales de motivación. Podría entenderse que había llegado a las instituciones educativas el producto directo o indirecto de formas de disciplinamiento que se encontraban desde años en nuestra vida cotidiana y también, reconozcámoslo, en las deficiencias de nuestras instituciones democráticas que relegaron la autonomía y la libertad.

Decir No. El imperativo de la desobediencia, la obra más reciente de Javier de Lucas denuncia esas formas de disciplinamiento a la vez que defiende una ciudadanía crítica. El libro nos habla en distintas claves de la importancia del demos, de llevar a sus últimas consecuencias el núcleo mismo de la democracia, la lucha por los derechos, también los sociales y medioambientales, en definitiva, de la reapropiación del poder por parte de la ciudadanía apelando justamente a la capacidad de cuestionar, de disentir, de desobedecer. Esta obra se inscribe así, entre las preocupaciones básicas que transitan la trayectoria del profesor de Lucas.

Un libro pues que, como es característico de muchas otras obras del autor, no es solo para juristas o para cultivadores de la política, sino que se dirige a cualquier miembro de la comunidad política, a cualquier ciudadano tenga o no reconocida esa condición de manera administrativa. La pregunta por la obediencia es casi una pregunta sobre la condición humana, donde la idea de un posible acto de desobediencia no 
constituye, como subraya el autor, una anomalía, ni una actitud peligrosa, sino el fruto de nuestra afirmación como seres autónomos.

El lector encontrara a lo largo de esta obra una concepción articulada y compleja de la desobediencia civil, una forma especialmente justificada de decir no como sociedad, de ahí la exigencia de que sea civil (decirlo juntos). El núcleo del libro reside en la preocupación por apuntalar la idea de la democracia dialógica y deliberativa donde sea posible mantener un diálogo público y abierto (civil) sobre la distancia entre las razones y principios que dotan de legitimidad al sistema y las normas que se apartan de ellos. A ese respecto, la desobediencia, la disidencia aparece como una forma de hacer democracia. Esta idea poderosa se sitúa en el libro en manos de una ciudadanía que tiene sentido precisamente en el marco de la democracia profundizada y del Estado de Derecho y no al margen de ambos. La obra tiene dos partes. La primera se centra en la relación entre ciudadanía, democracia y deber de obediencia, a partir de una concepción de ciudadanía y de la democracia, claramente transformadas por la diversidad cultural y la cuestión social. En la segunda parte se ofrece un análisis de gran calado sobre diversas formas de desobediencia, sus fundamentos, límites y alcance. Una reflexión sobre la tensión entre obediencia y desobediencia y los argumentos sobre su justificación, mostrando lo imprescindible que resulta contextualizar tanto las razones que justifican la pretensión de obedecer, como la evolución de las manifestaciones de la disidencia, de la desobediencia como lucha por la democracia y lucha por los derechos.

Ciertamente el examen de las distintas formas de desobediencia justificada no se limita a su clasificación o presentación, (objeción de conciencia, derecho de resistencia frente a la ley y al soberano injusto, desobediencia civil) sino que ofrece al lector una aproximación filosófica, histórica, jurídica y política de todas esas formas, con una atención minuciosa a cada una acompañada de sus claves interpretativas. Como ejemplo, véase como se presenta la desobediencia como derecho de resistencia o rebelión desde Antígona a las revoluciones del siglo XVIII a través de autores como San Agustín, la escolástica tomista, los teólogos juristas españoles o Locke en el capítulo cuarto, a través de una argumentación rica en referencias y rigurosa, muestra del valor y la fuerza que el autor atribuye a la filosofía jurídica y política. Es decir, cada planteamiento se examina y pormenoriza tanto en casos, como en legislación y en movimientos sociales. El texto resulta así reflexivo y a la vez muy evocador a través de una extraordinaria riqueza de fuentes bibliográficas y esa forma tan interesante, a la que nos tiene habituados el autor, de 
poner en diálogo a una diversidad de autores que a lo largo de la historia han puesto el acento en la capacidad de dudar, de criticar y de desobedecer, unido a la plasmación de todo tipo de expresiones artísticas especialmente el cine y la literatura. En definitiva, esta obra es una muestra excelente del pensamiento crítico y de la fuerza de la razón práctica y se nos presenta como un balance, y la vez un inventario renovado, una puesta al día de toda la obra de Javier de Lucas. Señalaré tres aspectos de este libro en los que se plasma esta idea.

En primer lugar, como los lectores sabrán, la pregunta por la obediencia y por la autoridad del derecho no es un tema novedoso en la obra del autor. En 1981 en uno de sus trabajos ya se preguntaba, "¿Por qué obedecer las leyes de la mayoría?". Lo interesante de su enfoque, ya entonces era esa constatación de las limitaciones de la justificación en abstracto y de la necesidad de contextualizar en esta discusión sobre las razones que justifican la pretensión de obedecer. Como lo había hecho ya con anterioridad al hilo de la lucha por el reconocimiento de la objeción de conciencia en nuestro país (1988), o sobre la insumisión como desobediencia civil en democracia (1985, 1992, 2002). O como muchas de sus publicaciones en las que ha reflexionado sobre ciudadanía, democracia y deber de obediencia, por citar una de las últimas "¿Qué es y que no es desobediencia civil?" (2019) y que este libro da continuidad y culmina.

En segundo lugar, esa misma constatación de contextualización le lleva a una atención preferente a todo cuanto ocurre y acontece. A lo largo del libro (pero podríamos decir a largo de toda su obra), y en especial en la segunda parte donde se atiende a la evolución de las manifestaciones de la disidencia, de la desobediencia como lucha por la democracia y por los derechos se muestra cuestiones de gran calado teórico a travesadas por los acontecimientos, los movimientos sociales, las corrientes de pensamiento. Así, se presenta una hibridación entre tipos ideales y acciones reales, prestando atención, por ejemplo, a los movimientos sociales, las nuevas oleadas de indignación, el altermundismo, las primaveras árabes, el 15M, las banlieues, el movimiento de derechos civiles impulsado por el Dr. King, y si el autor hubiera seguido escribiendo, no hay duda de que tendría mucho que decir sobre la situación de pandemia ocasionada por el covid19, tal como ha hecho a través de numerosos artículos en este proceso vital de confinamiento. El movimiento contra las ejecuciones hipotecarias de la plataforma PAH, la campaña por la sanidad universal a raíz del Real Decreto 16/2012 o el procés catalán, se proponen como casos que le permiten un ejercicio de claridad conceptual no solo interesante sino sobre todo imprescindible. El lector 
se contagia, así, de un interés por todo cuando ocurre, porque el autor le hace sentir que nada puede resultar indiferente o ajeno, que hay que mantenerse alerta prestando atención cada día ante lo que resulta inquietante, sin decaer en el compromiso con los más débiles.

En tercer lugar, el libro tiene un sentido descriptivo, pero también claramente normativo y prospectivo, algo propio del pensamiento crítico que la obra simboliza y que busca dar respuesta a la cuestión de cómo podría ser una ciudadanía plena o un modelo de ciudadanía para el futuro, en contextos en constante transformación por razones tan variadas como la globalización ligada a la gran recesión, la diversidad cultural como diversidad profunda, la crisis climática y el impacto de esos presupuestos sobre el pacto social y político y los derechos constitutivos del vínculo social.

Estos tres aspectos del libro del profesor De Lucas están atravesados por su preocupación central, un compromiso con la actitud de disidencia, de desobediencia como actitud vital; al modo de Fromm del que ofrece un análisis espléndido en el capítulo 1, y de desobediencia civil, subrayando este adjetivo junto a Bedau en el capítulo 4. En este compromiso le acompañan Honneth, Taylor, Fraser, Dahl, Todorov, Balibar, Rancière, Rawls, Habermas o Brown por citar solo algunos de los autores más próximos en el tiempo. Parece indudable que la obediencia a las normas jurídicas tiene, por así decir, una presunción de que éstas se ajustan a los principios que nosotros mismos hemos instituido y por ello les atribuimos ser fuente de legitimidad. Pero en la medida en que nuestras sociedades son más libres y más plurales, y no van a dejar de serlo, pueden ser, como advierte el libro, mayores los desacuerdos, los déficits de legitimidad y las posibilidades de invocación de la desobediencia.

Resulta esclarecedor el riguroso análisis que se ofrece sobre distintas formas de desobediencia, de disidencia, resistencia al poder (distintas en clave histórica, filosófica, analítica, pragmática). Entre estas modalidades se atiende a las siguientes: el conflicto de conciencia frente a la ley injusta, como una forma individual de decir no, que estaría representada por la objeción de conciencia; el derecho de resistencia frente al poder ilegítimo (como formas individuales y colectivas de decir no) que tienen un carácter político; el derecho de resistencia vinculado a la tesis de que una ley injusta o un soberano injusto no son ley, no son soberano y por lo tanto, se cuestiona su validez (rebelión, tiranicidio como actos legítimos y justificados); el derecho de resistencia, como conflicto entre ordenes normativos que ha ido transformando su configuración. Un derecho moderno de resistencia que tiene sus semillas en las revoluciones norteamericana y francesa que constituyen el punto de inflexión del derecho a la protesta y 
a la resistencia, el derecho a decir no (juntos) que desembocará en la construcción de modelos democráticos. Tránsito al que el libro presta una especial atención y del que ofrece pautas interpretativas muy esclarecedoras.

Se llega, de este modo, a la propuesta de la desobediencia civil como derecho a la protesta en la democracia, como expresión de desacuerdo político y no solo moral. Resuena el eco de David Henry Thoreau que invoca en su ensayo de 1847 la fidelidad a los principios de los padres fundadores de la revolución norteamericana frente a la soberanía inglesa. Me parece enteramente recuperable la idea nuclear que la desobediencia es una conducta exigente, pública, pacífica y que acepta la sanción para probar su coherencia, cuyo objetivo no es cambiar el régimen político, ni tampoco excepcionar la aplicación de un deber a un caso concreto.

Resulta especialmente interesante la explicación sobre como se enraíza la doctrina contemporánea de la desobediencia civil en la obra de Hugo Adam Bedau quien ya en 1961 estableciera los elementos basilares de esta categoría considerando que la desobediencia civil es expresión genuina del espíritu de la democracia y del Derecho. Russell, Dworkin, Habermas o Rawls con Bedau, aunque con algunas variantes, se refieren a la desobediencia civil, como nos explica el libro, como modalidad de desobediencia o como cuestionamiento directo o indirecto de una norma, una sentencia, una práctica administrativa de forma pública y pacífica con el objetivo de que la norma o mandato sea anulado, alegando que no se ajusta al marco jurídico común del que emana la legitimidad. La desobediencia civil se separa así claramente de formas de desobediencia como la delincuencia o la violencia revolucionaria.

Sin duda, una aportación del libro, en este sentido, es la fuerza de los argumentos a través de los que se subraya el carácter civil de la desobediencia. Es en este ámbito donde Javier de Lucas pone el acento y explicita no solo la importancia de esta dimensión de civilidad, sino que en ella descansa la diferenciación con otras formas de desobediencia. La exigencia de ser pacífica, pública, abierta, no violenta, da cuenta de una actitud que no pretende burlar la ley sino exponerla a la crítica, apelar a la mayoría y suscitar la reflexión sobre la pertinencia de revertir una decisión en coherencia con los principios de un ordenamiento-jurídico y político. La aceptación del castigo constituirá finalmente una muestra del compromiso social del ciudadano desobediente. Sin embargo, esta ultima exigencia, la aceptación del castigo, es objeto, obviamente, de controversia de la que se da buena cuenta en el libro. Para el profesor De Lucas asumir el castigo evidencia que el desobediente civil comparte la legitimidad del sistema, no 
pretende cambiar el sistema jurídico-político en su conjunto, sino que su objetivo es mejorarlo. Al aceptar ese castigo, -continua el autor en línea con King- el desobediente civil demuestra la desproporción de la violencia jurídico-institucional con la que se protege una norma cuya injusticia se quiere poner en evidencia, lo que contribuye a revisar el fundamento de la norma cuestionada.

Como he señalado se trata de una cuestión polémica que Javier de Lucas afronta en ulterior sentido cuando advierte que identificar la asunción del castigo como un elemento propio de la desobediencia civil no debe significar que la respuesta de la autoridad deba articularse necesariamente a través de la vía punitiva, incluso jurídica en sentido amplio, pues también caben respuestas de orden político. Algo que en el contexto del punitivismo actual resulta una salvedad del todo necesaria. De ahí la importancia de rehacer los puentes de comunicación de una democracia dialógica y deliberativa y la apelación a mantener el rasgo de asumir el castigo como actitud civil.

Por tanto, la desobediencia civil como instrumento democrático es centralmente civil. El texto desgrana los argumentos sobre las modalidades de desobediencia que carecen de este atributo, modalidades que no sirven a construir una sociedad decente o a recuperar el demos. El libro también da el salto hacia la desobediencia civil más allá del estado nacional y el derecho interno a través de la defensa de causas más transversales, intergeneracionales y universales, como pueden ser: el feminismo, el ecologismo o la movilidad humana. Causas que llevan, y aquí el eco de Scheuerman, a revalorizar la desobediencia civil cuya dimensión global no obedece solo porque se utilice en causas que tienen alcance planetario, sino también porque los ciudadanos actúan en defensa de unos principios globales de legitimidad que superan el marco de legitimidad de los ordenamientos constitucionales estatales.

Por tanto, un ámbito que va a seguir necesitado de reflexiones sólidas y propuestas racionales como las que se vierten en este libro. Se nos advierte así sobre dos paradojas, de un lado, la capacidad de la democracia de ponerse a prueba a si misma, la capacidad de resurgir de sus crisis con mayor calidad, y como resulta relevante la actividad de resistencia de la ciudadanía que la convierten en un sistema en permanente corrección, en una tarea siempre inacabada. Y la segunda es la paradoja de los límites del estado nacional para pensar en un nosotros y la exigencia de pensar a toda la humanidad como sujeto, y hacerlo como imperativo de la desobediencia civil de hoy, para resistir ante las formas más graves de negación de la universalidad. 
Paradojas de nuestro tiempo o desafíos de un calado enorme, que como plantea el profesor Javier de Lucas exigen "una nueva gramática de la democracia". Con esta nueva gramática está comprometida toda la obra del autor y este libro es una pieza fundamental de los principios, elementos y combinaciones de esa lengua. 